\title{
Rupture process of the July 2003 northern Miyagi earthquake sequence, NE Japan, estimated from double-difference hypocenter locations
}

\author{
Tomomi Okada, Norihito Umino, and Akira Hasegawa \\ Research Center for Prediction of Earthquakes and Volcanic Eruptions, Graduate School of Science, Tohoku University, Sendai 980-8578, Japan
}

(Received September 30, 2003; Revised December 25, 2003; Accepted December 26, 2003)

\begin{abstract}
A shallow M6.4 inland earthquake occurred on July 26, 2003 in the northern part of Miyagi Prefecture, northeastern Japan. We precisely located hypocenters of this event, its foreshocks and aftershocks by applying the double-difference method to data from temporal seismic stations and the seismic stations of Tohoku Univ., JMA and Hi-net. Aftershocks thus located are distributed in an area with about $15 \mathrm{~km} \times 15 \mathrm{~km}$ and their depths range from 2 to $13 \mathrm{~km}$. They are distributed along a curved plane dipping westward to north-westward with a dip of about 50 degrees. Its strike is about N-S in the northern part and about NNE-SSW in the southern part. The M5.6 foreshock, which occurred 7 hours before the main shock, is located near the center of the whole aftershock area at which the strike of the aftershock alignment changes abruptly. Aftershocks for the M5.6 foreshock are distributed in the southern part of the whole aftershock area. The main shock is located in the southern part of the aftershock area. It occurred near the edge of the area of aftershocks for the M5.6 foreshock. Aftershocks following the main shock are mainly distributed in the northern part of the aftershock area. The largest aftershock (M5.5) is located at the northern end of the whole aftershock area. After the occurrence of the main shock, few aftershocks occurred in the area of aftershocks for the M5.6 foreshock. We also determined fault plane solutions for the events that occurred during the sequence from the M5.6 foreshock to the largest (M5.5) aftershock. The spatial variation of focal mechanism is consistent with the curved geometry of the fault plane estimated from the aftershock distribution.
\end{abstract}

Key words: The 2003 northern Miyagi earthquake, hypocenter distribution, double-difference method, foreshock, inversion tectonics, the Ishinomaki-wan Fault.

\section{Introduction}

A shallow M6.4 earthquake (hereafter we call it the 2003 northern Miyagi earthquake) of July 26, 2003 and its foreshocks and aftershocks occurred near the border between Yamoto and Naruse towns in Miyagi Prefecture, northeastern Japan. This earthquake was located in the upper crust and one of the typical inland earthquakes that have frequently occurred in northeastern Japan (Hasegawa et al., 2000). In this earthquake sequence, a large foreshock with M5.6 occurred 7 hours before the occurrence of the main shock and the largest aftershock with M5.5 occurred 10 hours after the occurrence of the main shock. These three events registered the maximum intensities of 6 in the JMA (Japan Meteorological Agency) scale and damaged over 1000 buildings situated above their focal area.

We need precise hypocenter locations to understand the rupture process of this earthquake sequence in detail. Hypocenter distribution obtained by the seismic networks that were routinely operated shows that most of the events are located at about $12 \mathrm{~km}$ depth. This distribution is probably different from the true distribution, because there are no seismic stations above the focal area. In fact, the station closest to the focal area is about $15 \mathrm{~km}$ far from the focal area.

To improve the accuracy of hypocenter determination and

Copy right(C) The Society of Geomagnetism and Earth, Planetary and Space Sciences (SGEPSS); The Seismological Society of Japan; The Volcanological Society of Japan; The Geodetic Society of Japan; The Japanese Society for Planetary Sciences. obtain more detailed information about the 2003 northern Miyagi earthquake sequence, 13 seismic stations with data loggers and a seismic station with a satellite telemetry system were deployed after the main shock occurrence right above the focal area (Umino et al., 2003). In the present paper, we investigate detailed distribution of hypocenters of the 2003 northern Miyagi earthquake sequence using data from these temporary seismic stations and discuss the rupture process of the sequence.

\section{Hypocenter Relocations Using Temporary Ob- servation Data}

First, we precisely relocated hypocenters of aftershocks which occurred after the temporary seismic stations were deployed. We used arrival time data picked manually from the digital waveforms recorded at the temporary seismic stations and those for the stations of Tohoku University, JMA and Hi-net (High Sensitivity Seismograph network in Japan) whose epicentral distances were less than $20 \mathrm{~km}$ (Fig. 1). We adopted the double-difference method (Waldhauser and Ellsworth, 2000; hereafter we call it the DD method) for the hypocenter determinations. The "double-difference" means the difference for a station between the observed and calculated travel time difference between a pair of events. The DD method cancels the common mode errors in calculating travel times using 1D velocity model and avoids the need of introduction of station corrections. The seismic velocity model routinely used in the Tohoku University seismic net- 


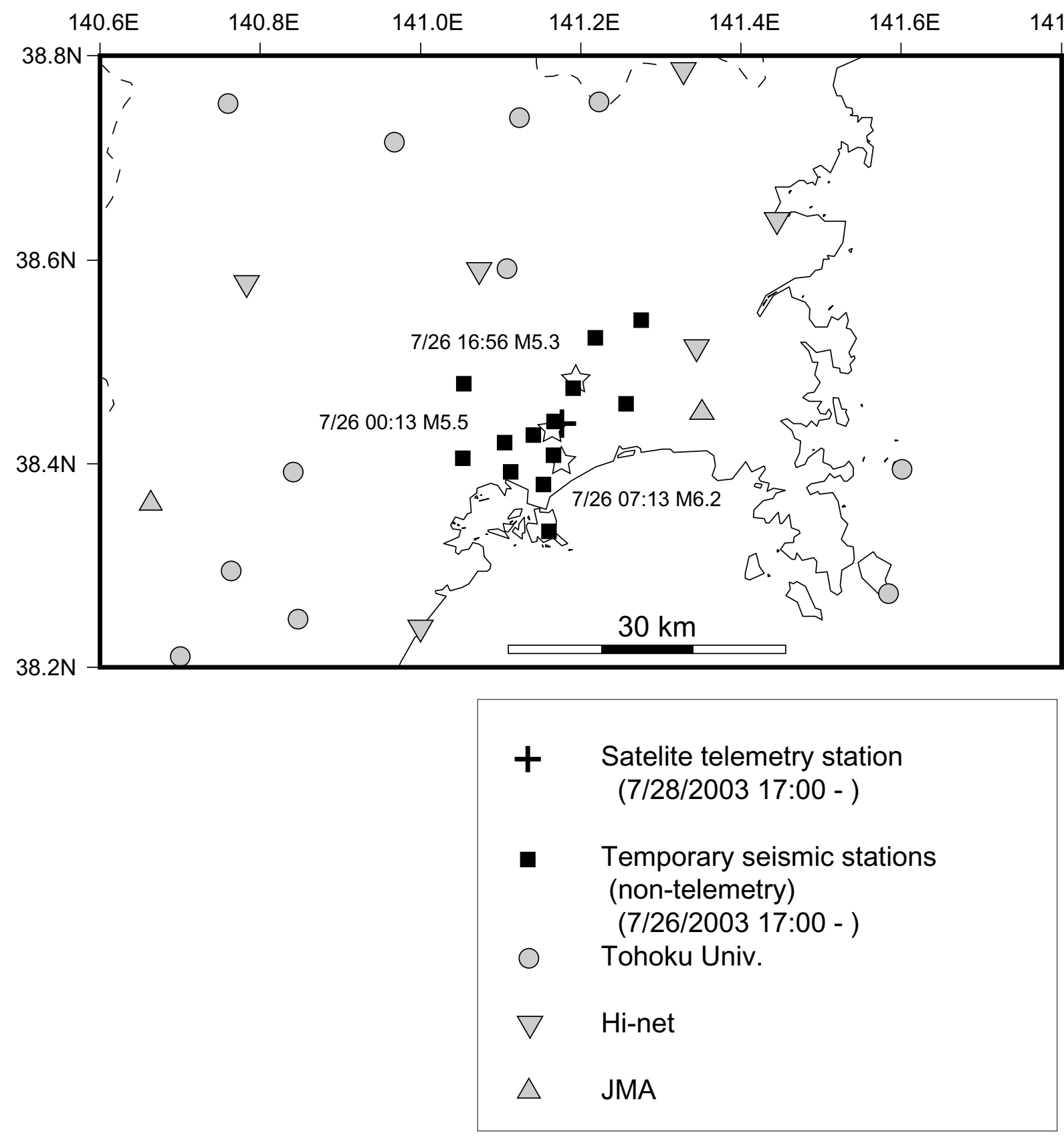

Fig. 1. Locations of stations above and around the focal area of the 2003 northern Miyagi earthquake. A cross and squares show a temporary station with satellite telemetry system and temporary stations with data loggers, respectively. Circles, triangles and reversed triangles denote stations of Tohoku Univ., JMA and Hi-net, respectively. Stars show hypocenters of the 2003 northern Miyagi earthquake, the M5.6 foreshock and the largest aftershock.

work (Hasegawa et al., 1978) was adopted for the calculation of travel times. Events that occurred during the period from 17:00, July 26 to 8:00, August 18 were relocated. The number of events located is 853 . The number of pairs of $P$ wave arrival times is 88627 and that of $S$-wave arrival times is 67596 .

Figure 2 shows the distribution of relocated hypocenters for aftershocks of the 2003 northern Miyagi earthquake. Relocated aftershocks are distributed in an area of about $15 \mathrm{~km} \times 15 \mathrm{~km}$ and their focal depths range from 2 to $13 \mathrm{~km}$. The strike of the aftershock distribution of the present earthquake sequence varies spatially as shown by isobath contour lines in Fig. 2. Aftershocks in the northern part are distributed along a westward dipping plane with a dip of about
50 degrees. On the contrary, those in the southern part are along a plane dipping to the northwest with a dip of about 50 degrees. Aftershock alignment seems to incline more gradually near the lower boundary of the aftershock area like listric fault (e.g. Sato et al., 2002). The lower boundary of the aftershock area nearly corresponds to the bottom of the seismogenic zone in the upper crust surrounding the focal area, indicating that it corresponds to the brittle-ductile transition (Hasegawa et al., 2000). Aftershocks are not distributed homogeneously along the fault plane. In particular, the aftershock distribution is complex in depth range between 5 and $10 \mathrm{~km}$. Some of these events form off-plane seismicity along planes like conjugate faults. 
(a)

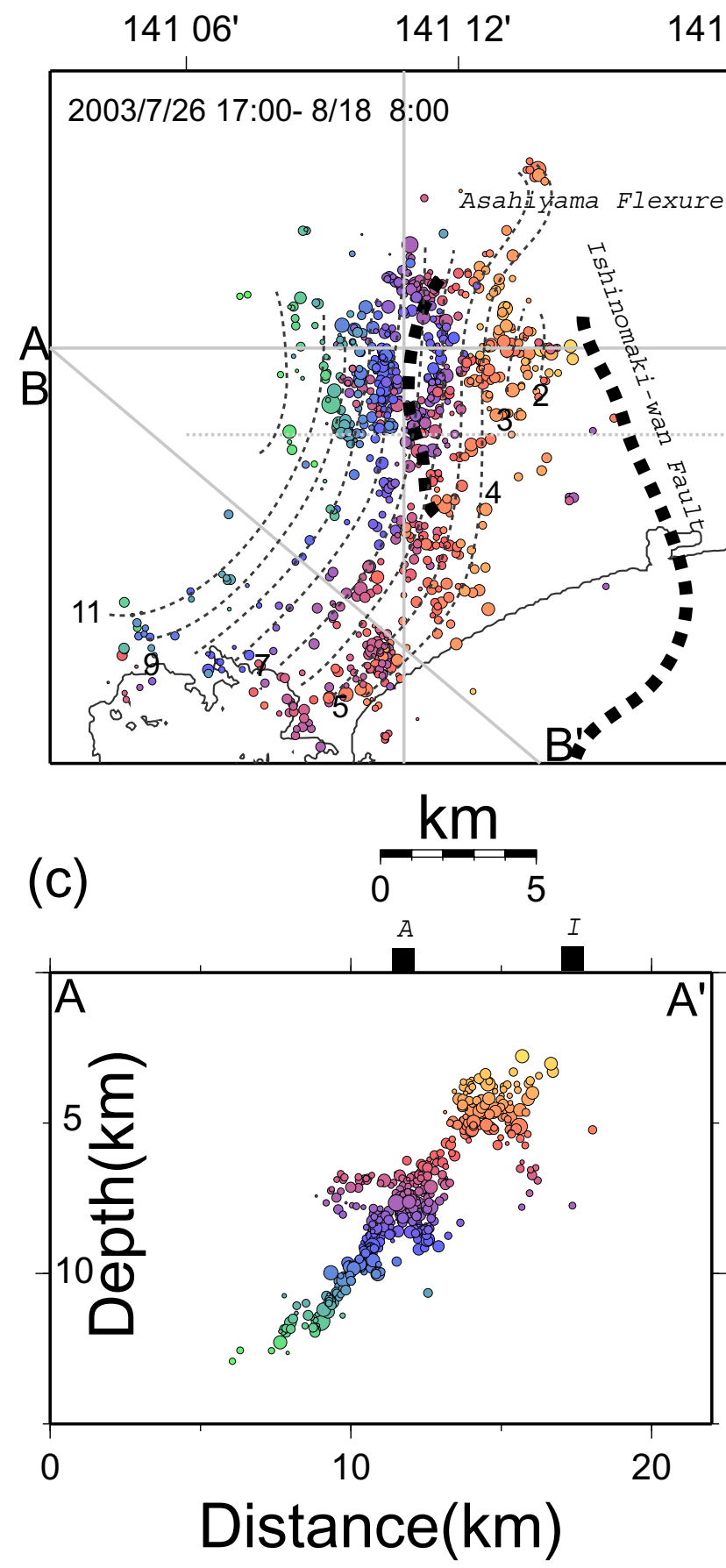

(b)

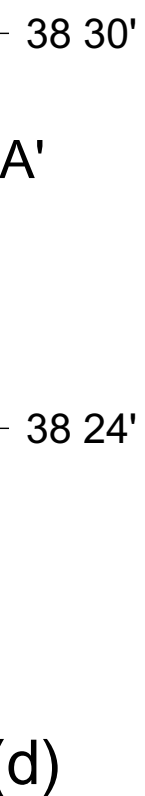

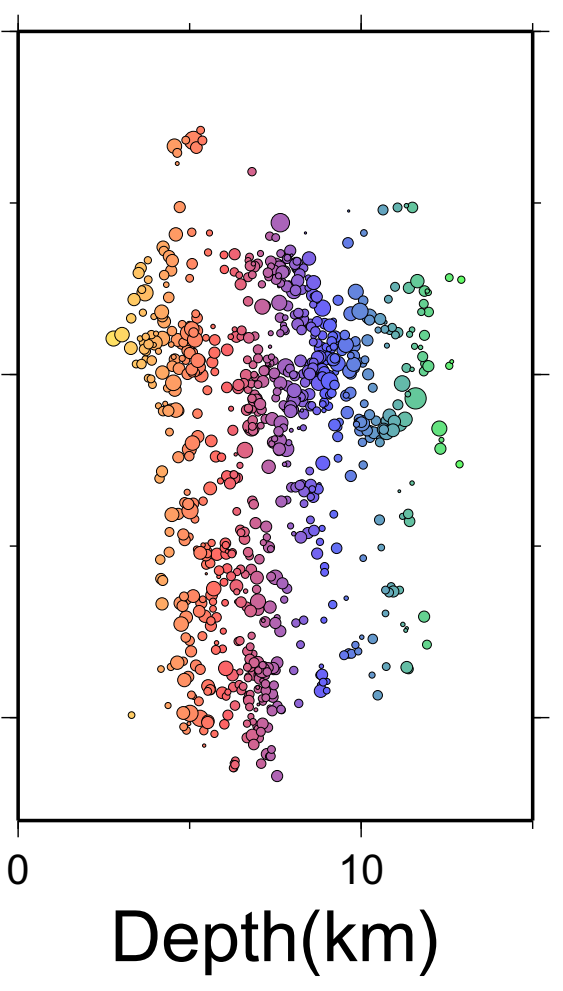

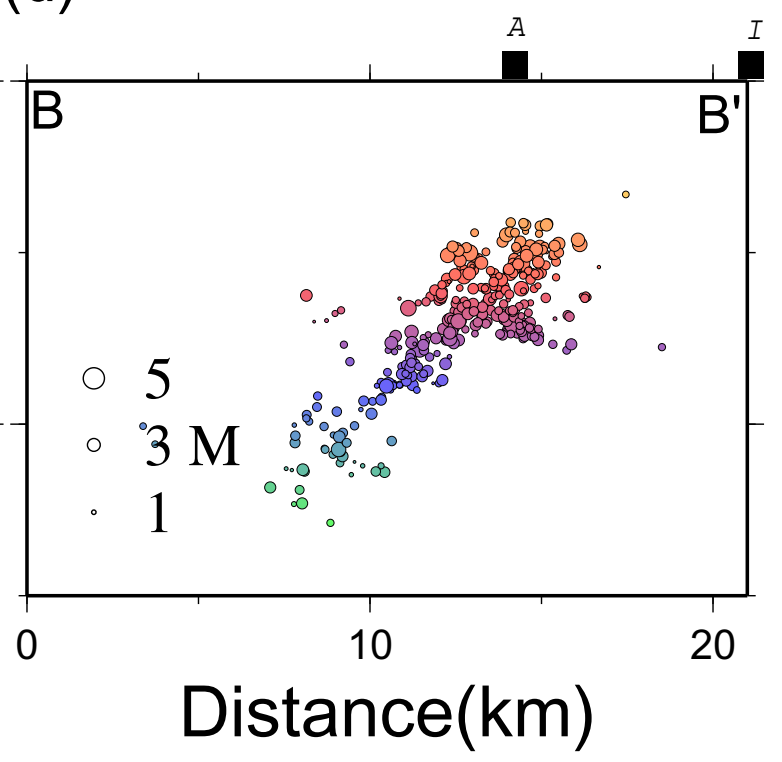

Fig. 2. Hypocenter distribution of aftershocks relocated by the DD method. Events for the period from 17:00, July 26 (JST) to 8:00, August 18 (JST) are shown. Colors of symbols show depths of the hypocenters. Sizes of symbols are proportional to their magnitudes. (a) Epicenter distribution. Thin broken lines show the contours of focal depth of the aftershocks at an interval of $1 \mathrm{~km}$. Bold broken lines show some geological structures in and around the focal area of the 2003 northern Miyagi earthquake (Geological Survey of Japan, 1990, 1992; Sato et al., 2002). (b) NS vertical cross section. (c) Vertical cross section along line A-A' for events located in the northern side of the dotted line in Fig. 2(a). Boxes labeled by 'A' and 'I' on the top show the locations of the Asahiyama Flexure and that of the Ishinomaki-wan Fault, respectively. (d) Vertical cross section along line B-B' for events located in the southern side of the dotted line in Fig. 2(a).

\section{Hypocenter Relocations for Events before the Temporary Observations}

We started to deploy the temporary stations at about 17:00 (JST), July 26, 2003. It is difficult to precisely determine hypocenter locations without nearby, dense seismic stations by conventional location methods. We tried to determine hypocenters of events that occurred before the deployment of the temporary stations (hereafter we call them the prelogger events) by devising the location method. We adopted the DD method to relocate the pre-logger events also. In 
(a)
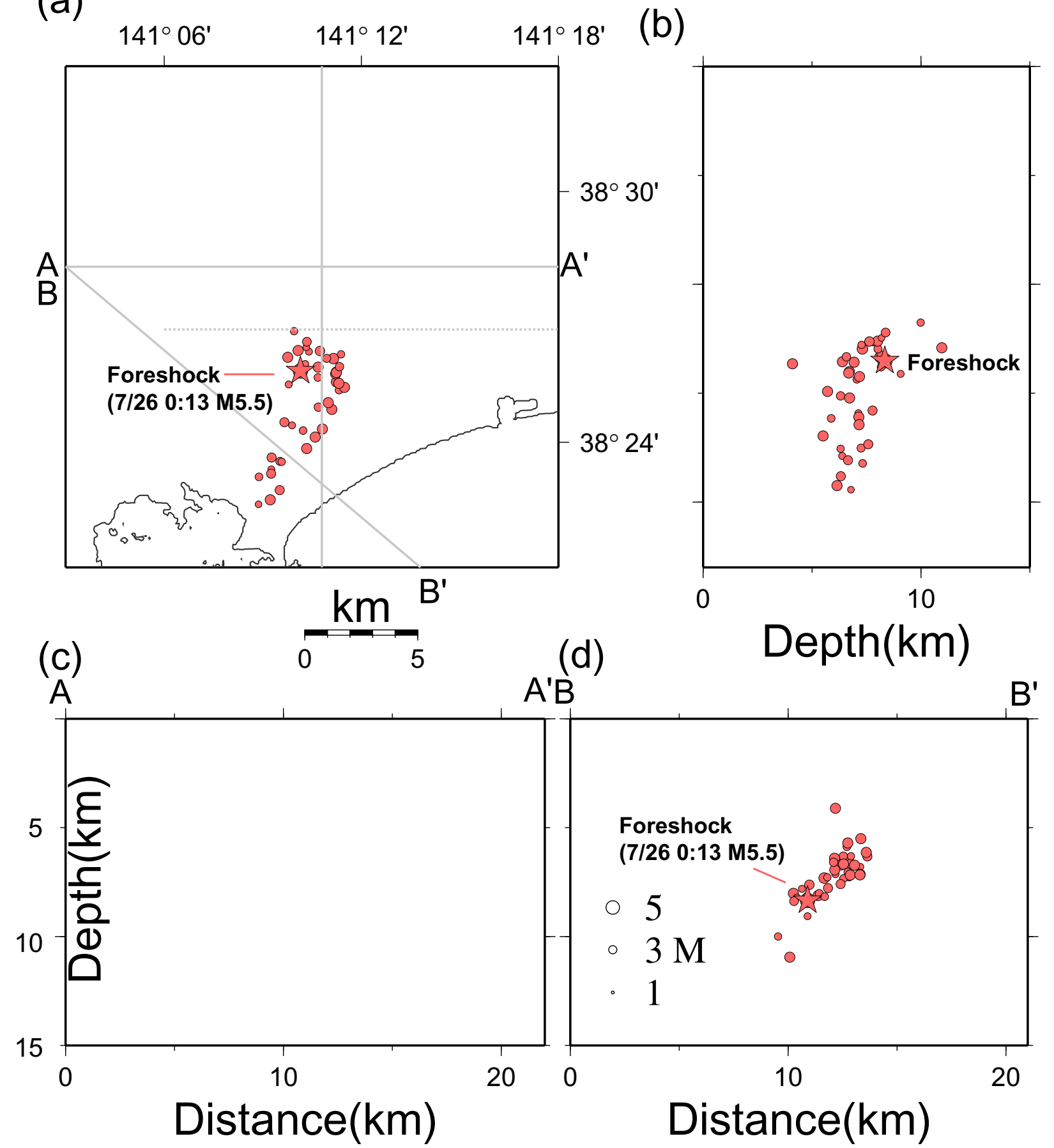

Fig. 3. Hypocenter distribution of the M5.6 foreshock and its aftershocks. Events for the period from 00:13, July 26 to 7:12, July 26 are shown. (a), (b), (c) and (d) are shown in the same manner as those of Fig. 2.

this relocation procedure, we also included events that occurred while the temporary seismic stations were operated (hereafter we call them the co-logger events), and pre- and co-logger events were located simultaneously by applying the DD method. Plausible initial hypocenter locations are needed to obtain reliable results from the DD method. Epicenters can be accurately determined to some extent even without the nearby temporary seismic stations. Therefore, we adopted these epicenters as the initial values. Initial depth of a pre-logger event was assumed to be the same as that of a co-logger event whose epicenter is closest to the pre-logger event. All the events with magnitudes larger than or equal to 2.5 during the period from the occurrence time of M5.6 foreshock (0:13, July 26) to 8:00, August 18 were relocated. The number of events thus relocated is 879 , including the co-logger events. We used $P$-wave arrival time data picked manually for the stations with epicentral distances less than $150 \mathrm{~km}$. In this case we did not use the $S$-wave arrival time data because the accuracy of picking of $S$-wave onset was worse, particularly for larger events, due to their long and complex source durations. The number of pairs of $P$-wave arrival times thus used is 370,431 . 

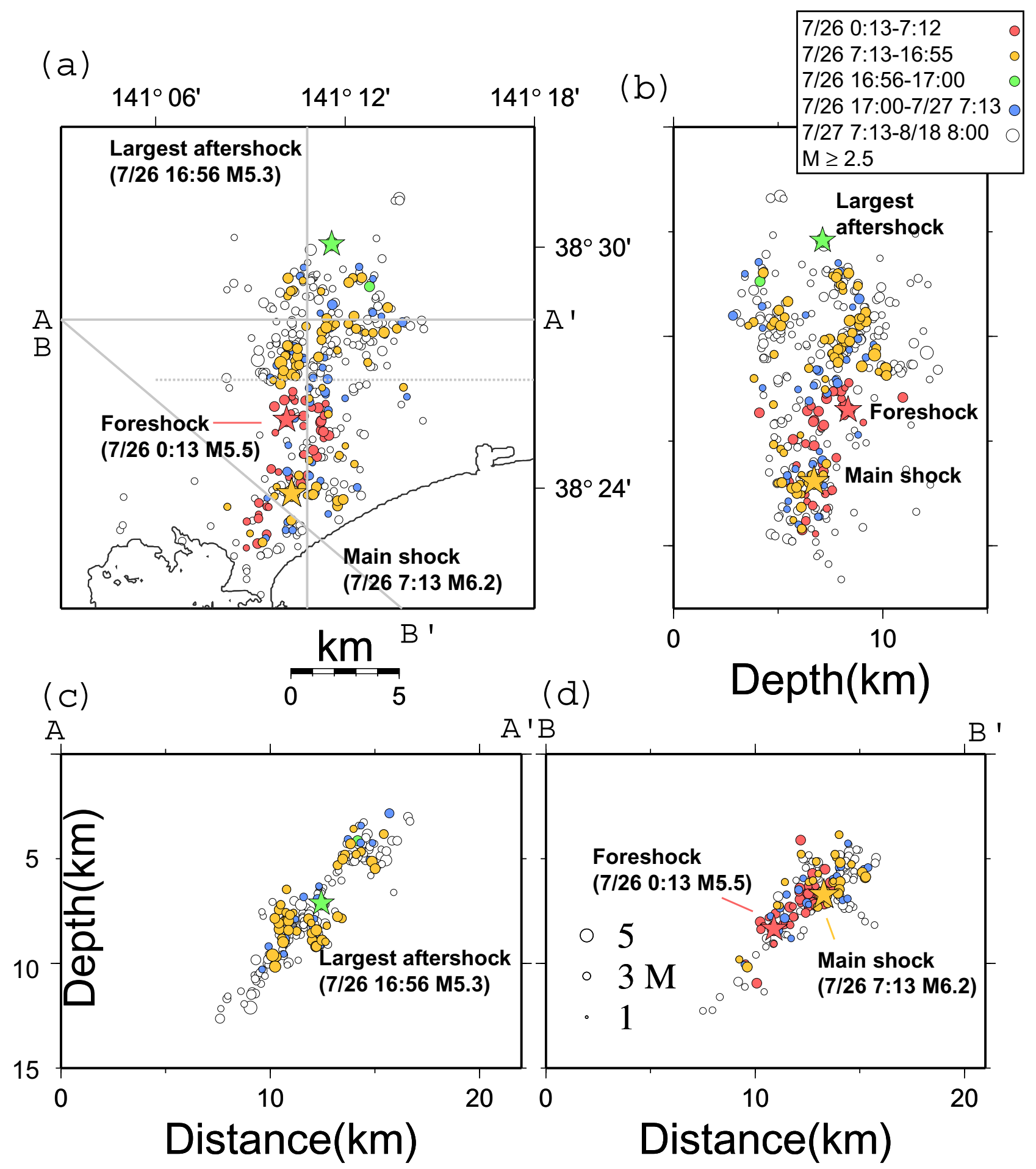

Fig. 4. Hypocenter distribution for the 2003 northern Miyagi earthquake sequence. Events for the period from the M5.6 foreshock to 8:00, August 18 (JST) are shown. Yellow symbols show the main shock and aftershocks following it, while the M5.6 foreshock and events following it are denoted by red symbols, respectively. Green symbols show the largest aftershock and events which occurred just after it. Blue symbols show events which occurred within 1 day after the main shock occurrence. (a), (b), (c) and (d) are shown in the same manner as those of Fig. 2 except for the symbol colors.

Figure 3 shows hypocenters of events that occurred for the period from the M5.6 foreshock (0:13, July 26) to just before the mainshock (7:12, July 26). The M5.6 foreshock is located near the center of the whole aftershock area, at which the strike of the aftershock alignment changes. Figure 3 shows that aftershocks following the M5.6 foreshock are distributed in the southern part of the whole aftershock area.

Figure 4 shows hypocenters of the entire events that oc- curred during the sequence from the M5.6 foreshock to aftershocks on August 18 and Figure 5 shows depth-time and NS (latitude)-time plots for these events. We can see the following characteristics. (1) The main shock is located in the southern part of the aftershock area and near the edge of the area where aftershocks following the M5.6 foreshock occurred. (2) Aftershocks following the main shock are distributed mainly in the northern part of the aftershock area. 


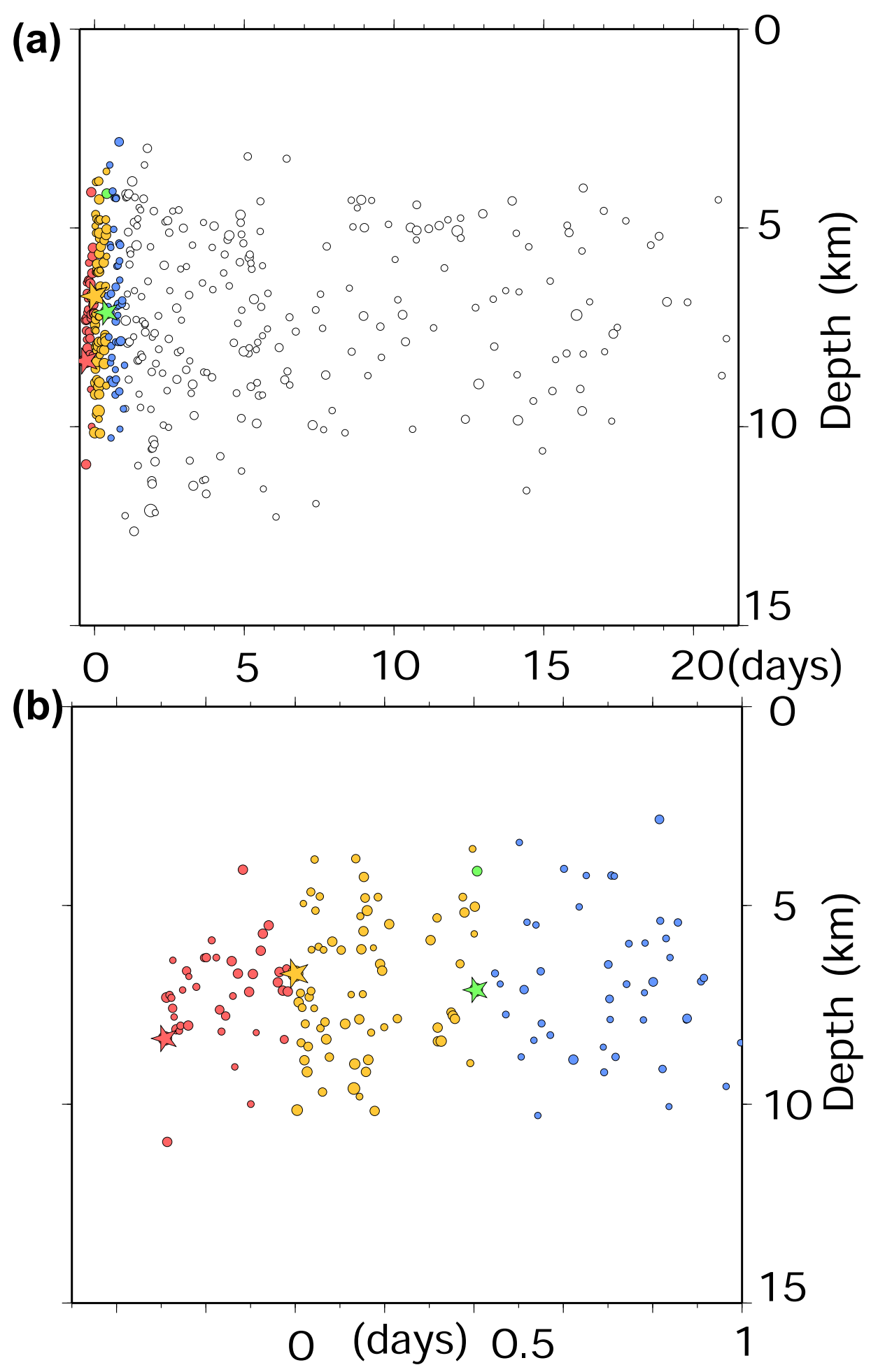

Fig. 5. (a) Depth-time plot for the events shown in Fig. 4. (b) Same as (a) but for events which occurred within 1 day after the mainshock occurrence. (c) NS (latitude)-time plot for events shown in Fig. 4. (d) Same as (c) but for events within 1 day after the mainshock occurrence. Symbol colours have the same meanings as those in Fig. 4.

(3) The largest aftershock (M5.5) is located at the northern end of the aftershock area. (4) Few aftershocks following the main shock are located in the area of aftershocks for the M5.6 foreshock. These all suggest that the rupture of the main shock was initiated at the edge of the foreshock rupture area and that the rupture area of the mainshock was bounded by the foreshock rupture area or was not overlapped with the foreshock rupture area. A similar result was obtained for a nearby earthquake sequence in 1998 (Okada et al., 2001a). The spatial extent of the aftershock area covered by aftershocks within about 3 weeks (white symbols) after the main shock occurrence seems to be larger than that within 1 day (colored symbols), particularly in the deeper portion (Fig. 4 and Fig. 5(a)). This shows that the expansion of the aftershock area (e.g. Tajima and Kanamori, 1985) was also the case for the 2003 northern Miyagi earthquake. 


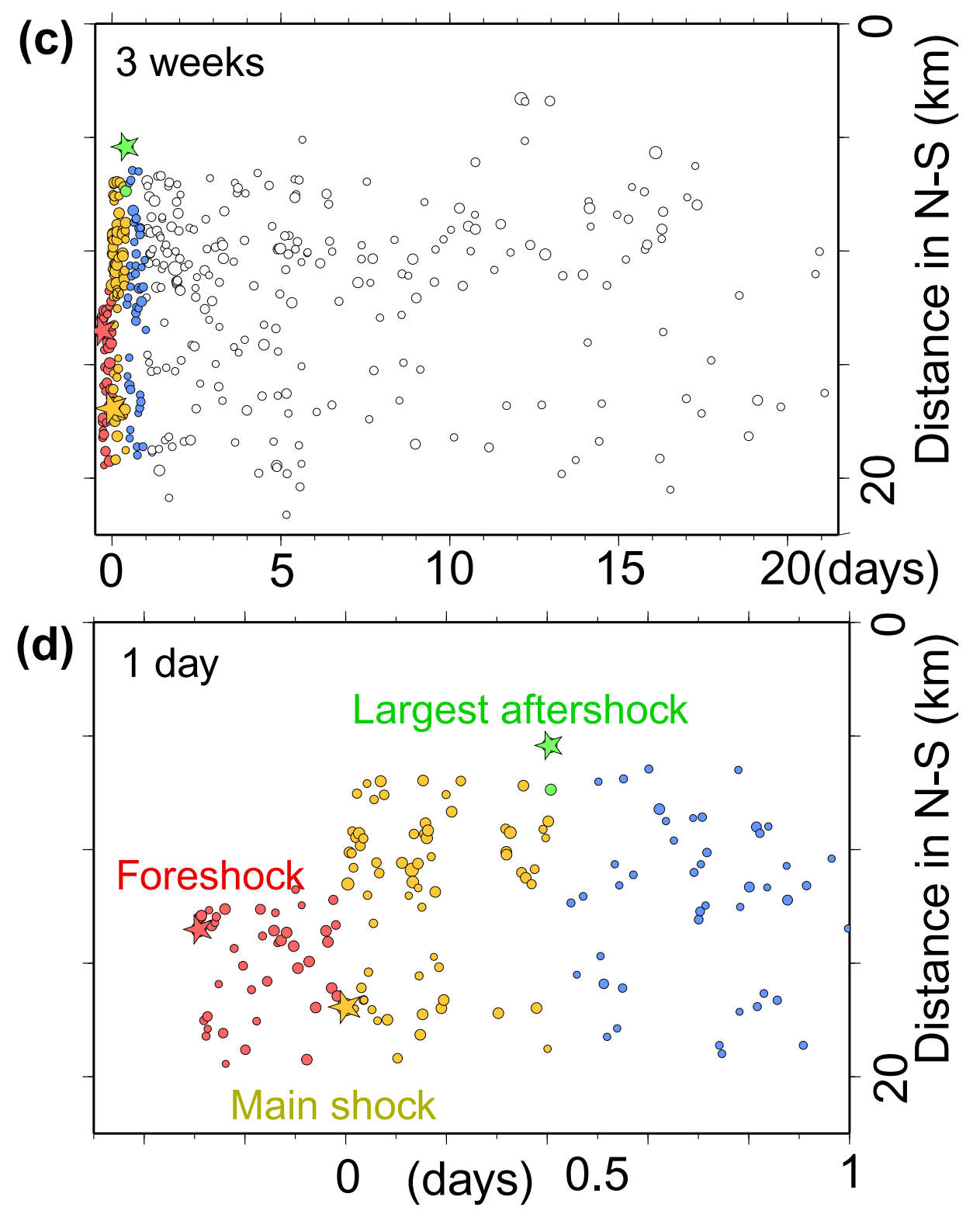

Fig. 5. (continued).

\section{Discussion}

We determined moment tensors for the three events (the main shock, the foreshock and the largest aftershock) using regional broad-band seismograms. The method is based on Dreger and Helmberger (1993) and we used the program TDMT-INVC developed by Dreger in our inversion (see also Okada et al., 2001b, 2003). Green's functions are calculated by using the program FKRPROG developed by Saikia (1994). The seismic velocity structure used in the calculation of Green's function is the same as that used in Fukuyama et al. (1998). The waveform data were provided from the Tohoku University's broad-band seismic network. The STS-1 or STS-2 type seismograph is deployed at each station. In the present analysis, waveform data were low-pass filtered with a pass-band between 0.02 and $0.05 \mathrm{~Hz}$ and resampled at a sampling rate of $1 \mathrm{~Hz}$.

The obtained moment tensor solutions are shown in Fig. 6. The three events have reverse-fault type solutions, which are typical for shallow crustal events in northeastern Japan.
However, the orientations of $P$-axis are different from each other. The $P$-axis is oriented in N-E for the main shock, NW-SE for the M5.6 foreshock and NE-SW for the largest aftershock, respectively. The geometry of a westward dipping nodal plane of the main shock corresponds to the aftershock alignment in the northern part. Also the nodal plane dipping to NW of the M5.6 foreshock corresponds to the aftershock alignment in the southern part. This feature probably shows that the centroid of the main shock is located in the northern part and the centroid of the foreshock is located in the southern part. There are some areas with few aftershocks, which probably correspond to the areas where large slip occurred in the rupture process of the main shock (e.g. Mendoza and Hartzell, 1988). Some off-plane aftershocks located near these areas would be caused by stress concentrations around the largely slipped areas. We determined the fault plane solutions of these three events from the polarity data for the first $P$-wave arrival and their relocated hypocenters. They are also shown in Fig. 6. Hereafter, we will call 
Largest aftershock (7/26 16:56 M5.3)

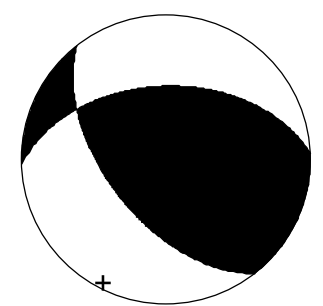

Fault plane sol.

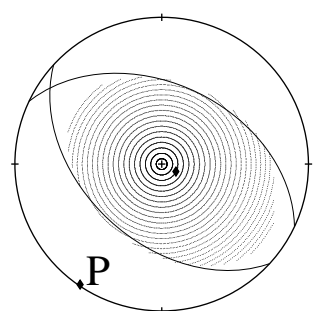

Moment tensor

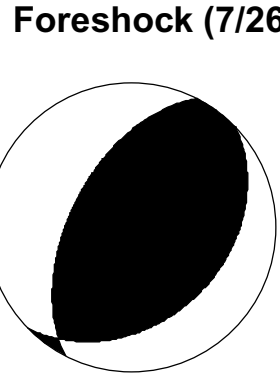

Fault plane sol.

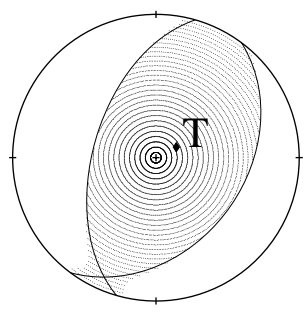

Moment tensor

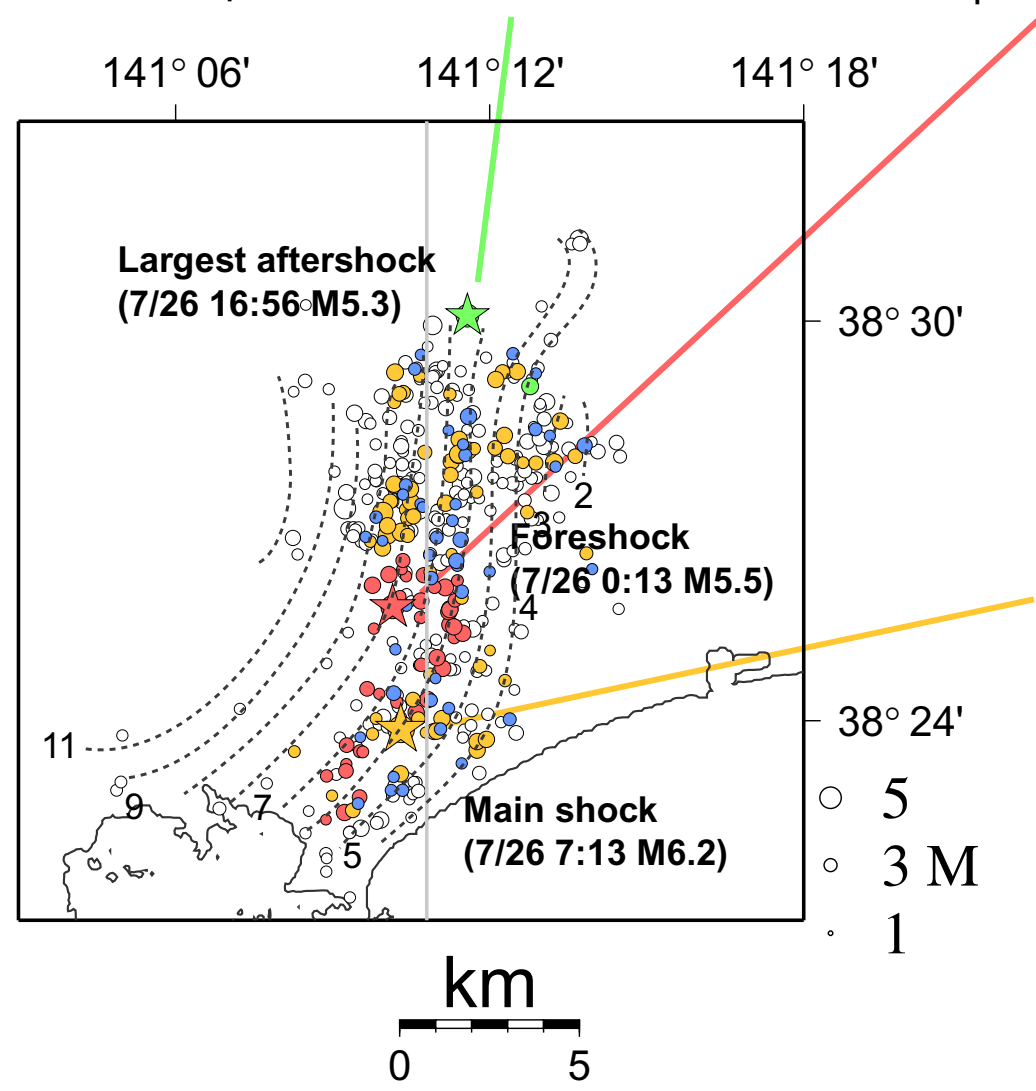

Main shock (7/26 7:13 M6.2)

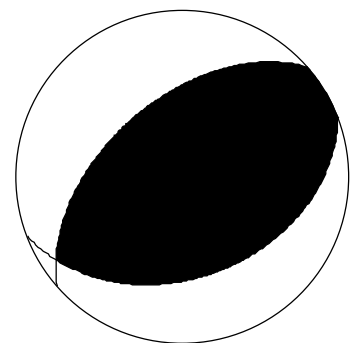

Fault plane sol.

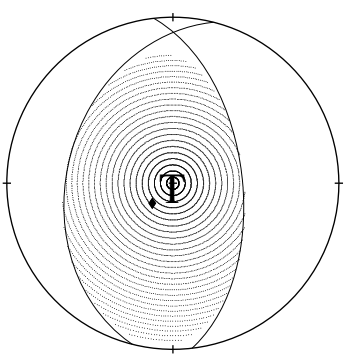

Moment tensor

Fig. 6. Fault plane solutions and moment tensor solutions of the mainshock, the M5.6 foreshock and the largest aftershock. They are shown by the equal-area projection onto the lower hemisphere. Index map is the same as Fig. 4(a).

the solutions estimated from initial motions 'fault plane solutions'. The fault plane solutions are nearly the same as the moment tensor solutions in the cases of the M5.6 foreshock and the largest aftershock, but they are clearly different in the case of the main shock. Here we should remember that the hypocenter of the main shock is located in the southern part of the aftershock area. This discrepancy between the moment tensor and fault plane solutions for the main shock can be explained as follows. The initial rupture of the main shock started in the southern part of the focal area where the fault plane strikes in NE-SW and dips to NW. Then the rupture extended to the northern part, forming the main rupture portion, where the fault plane strikes northward and dips westward. This interpretation is consistent with the results of source process inversions (e.g. Yagi et al., 2003). The complex geometry of the pre-existing fault might be the cause of the complicated sequence for the 2003 northern Miyagi earthquake.
We also determined fault plane solutions of other events that occurred before we installed the temporary seismic stations (Fig. 7). All of them have reverse-fault type solutions but their $P$-axis orientations are not the same. The events in the northern part of the aftershock area have $P$-axes oriented in E-W or NE-SW, while the events in the southern part have $P$-axes oriented in NW-SE. This tendency of spatial variation of focal mechanism is as also seen in the case of aftershocks that occurred after the temporal seismic stations were installed (Umino et al., 2003). The variation of focal mechanism is consistent with the curved geometry of the fault plane of the present sequence estimated from the aftershock distribution.

In and around the focal area of the 2003 northern Miyagi earthquake, there exist some geological structures related to active faults (e.g. Geological Survey of Japan, 1990, 1992). These faults were activated as normal faults in early Miocene under an extensional stress regime. Some of them have been 


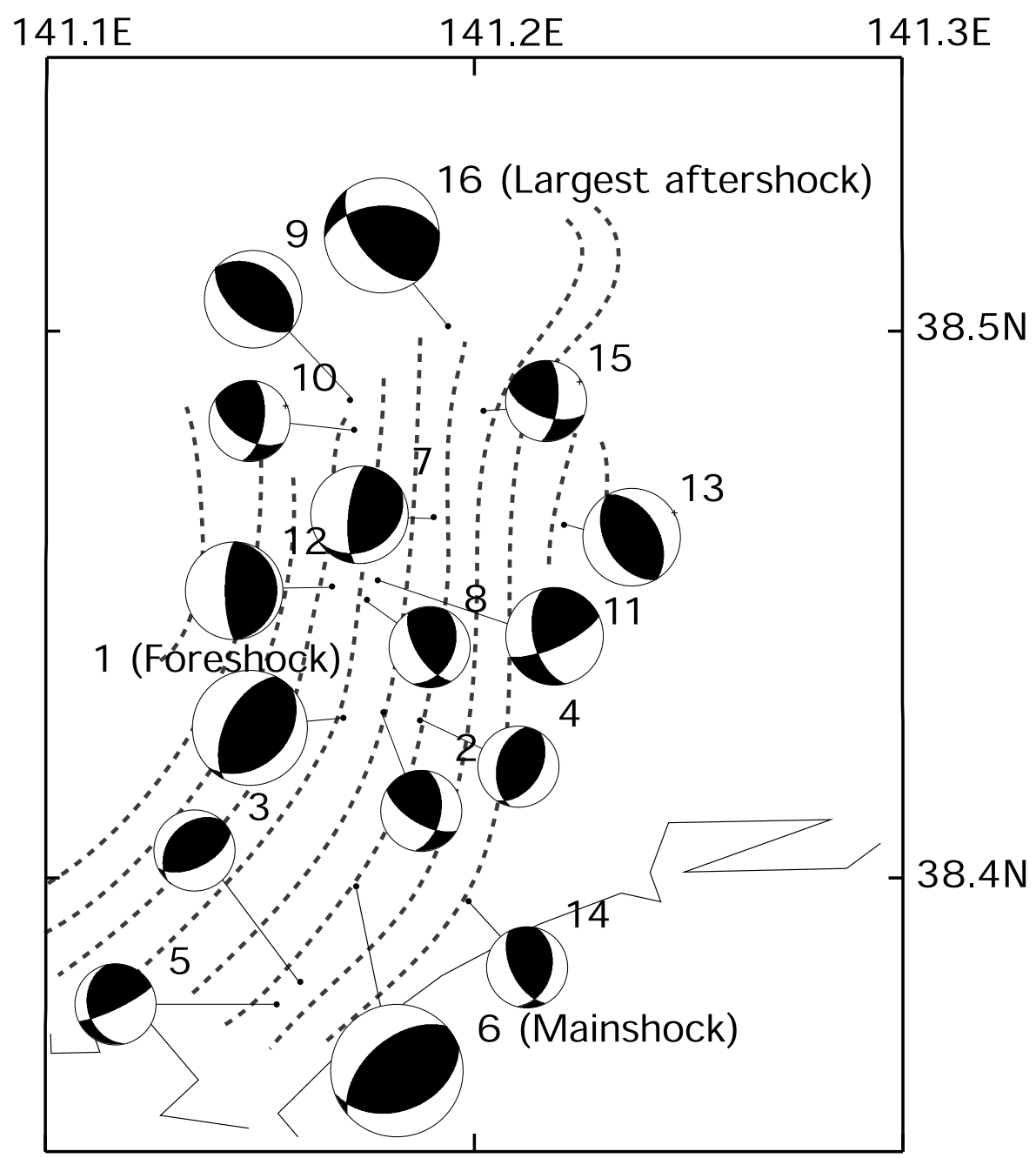

Fig. 7. Fault plane solutions of events that occurred before the temporary seismic stations were installed. Numerals attached show chronological order. Thin broken lines show the contours of focal depths of the aftershocks at an interval of $1 \mathrm{~km}$.

reactivated as reverse faults since the Pliocene due to shortening deformation under a compressional stress regime (e.g. Sato et al., 2002). Surface traces of these faults are shown in Fig. 2. One is the Asahiyama Flexure, which is located just above the focal area, and the other is the Ishinomakiwan Fault, which is located about $5 \mathrm{~km}$ east of the focal area. Figures 2(c) and (d) show that shallower extension of the aftershock zone seems to meet the surface trace of the Ishinomaki-wan Fault rather than that of the Asahiyama Flexure. This suggests that the present earthquake sequence is generated as the faulting of the Ishinomaki-wan Fault.

\section{Conclusions}

We precisely relocated hypocenters of the 2003 M6.4 northern Miyagi earthquake as well as its foreshocks and aftershocks by applying the double-difference method to the data from the temporary seismic stations deployed right above its focal area. We obtained westward dipping distribution of events with a dip of about 50 degrees, which coincides with one nodal plane of the 2003 northern Miyagi earthquake. The strike of the aftershock alignment changes with location; it is oriented in N-S in the northern part of the aftershock area and in NNE-SSW in the southern part. The hypocenter of the M5.6 foreshock, which occurred 7 hours before the main shock, is located in the center of the aftershock area, at which the strike of the aftershock alignment changes from N-S to NNE-SSW. Aftershocks following the M5.6 foreshock occurred in the southern part of the aftershock area. The main shock is located at the edge of the area of aftershocks for the M5.6 foreshock in the southern part. Aftershocks following the main shock occurred mainly in the northern part. The largest aftershock is located at the northern end of the entire aftershock area. One of the possible causes of the complicated sequence for the 2003 northern Miyagi earthquake is some complex geometry of the preexisting faults in this area.

Acknowledgments. We used data from a temporary seismic observation by Tohoku University, Yamagata University and NIED (National Research Institute for Earth Science and Disaster Prevention). We also used data from JMA and NIED. We are very grateful to the members for their effort for the observations. We used the program hypoDD (Waldhauser, 2001) to relocate hypocenters. Moment tensors were computed using the tdmt-invc package developed by D. Dreger of the Berkeley Seismological Laboratory, and Green's functions were computed using the FKRPROG software developed by C. Saikia with URS Granger, Woodward Clyde Federal Services. We are grateful to Prof. F. Tajima for valuable suggestions about moment tensor inversions and for fruitful discussions. We thank Prof. C. Thurber and the members of Deptartment 
of Geology and Geophysics, University of Wisconsin-Madison for many valuable discussions. We also thank Mr. T. Nakayama for his assistance in the moment tensor inversions. We are also grateful to Prof. Y. Honkura, Prof. A. Hasemi, Dr. T. Matsuzawa and an anonymous reviewer for the helpful comments.

\section{References}

Dreger, D. S. and D. V. Helmberger, Determination of source parameters at regional distances with single station or sparse network data, Journal of Geophysical Research, 98, 8107-8125, 1993.

Fukuyama, E., M. Ishida, D. S. Dreger, and H. Kawai, Automated seismic moment tensor determination by using on-line broad band seismic waveforms, J. Seism. Soc. Japan (Zisin), 51, 149-156, 1998 (in Japanese with English abstract).

Geological Survey of Japan, Geological map—off Kinkasan—, Geological Survey of Japan, Tsukuba, 1990.

Geological Survey of Japan, Geological Map-Ishinomaki, second edition, Geological Survey of Japan, Tsukuba, 1992.

Hasegawa, A., N. Umino, and A. Takagi, Double-planed structure of the deep seismic zone in the northeastern Japan arc, Tectonophysics, 47, 43$58,1978$.

Hasegawa, A., A. Yamamoto, N. Umino, S. Miura, S. Horiuchi, D. Zhao, and $\mathrm{H}$. Sato, Seismic activity and deformation process of the crust within the overriding plate in the northeastern Japan subduction zone, Tectonophysics, 319, 225-239, 2000

Mendoza, C. and S. H. Hartzell, Aftershock patterns and main shock faulting, Bulletin of Seismological Society of America, 78, 1438-1449, 1988.

Okada, T., N. Umino, Y. Ito, T. Matsuzawa, A. Hasegawa, and M. Kamiyama, Source processes of 15 September 1998 M5.0 Sendai, NE Japan, earthquake and its M3.8 foreshock by waveform inversion, Bulletin of Seismological Society of America, 91, 1607-1618, 2001a.

Okada, T., T. Yamashita, T. Nakayama, T. Matsuzawa, A. Hasegawa, and F. Tajima, Determination of moment tensors using Tohoku University's broad-band seismic network, Programme and Abstracts for Fall meeting of Seismlogical Society of Japan, P105, 2001b (in Japanese).

Okada, T., T. Matsuzawa, and A. Hasegawa, Comparison of source areas of M4.8+/- 0.1 repeating earthquakes off Kamaishi, NE Japan-Are asperities persistent features?, Earth and Planetary Science Letters, 213 361-374, 2003.

Saikia, C. K., Modified frequency-wavenumber algorithm for regional seismograms using Filon's quadrature: modeling of $\mathrm{Lg}$ waves in eastern North America, Geophysical Journal International, 118, 142-158, 1994

Sato, H., T. Imaizumi, T. Yoshida, H. Ito, and A. Hasegawa, Tectonic evolution and deep to shallow geometry of Nagamachi-Rifu Active Fault System, NE Japan, Earth Planets Space, 54, 1039-1043, 2002.

Tajima, F. and H. Kanamori, Global survey of aftershock area expansion patterns, Physics of Earth and Planerary Interiors, 40, 77-134, 1985.

Umino, N., T. Okada, J. Nakajima, S. Hori, T. Kono, T. Nakayama, N. Uchida, J. Shimizu, J. Suganomata, G. Shantha, K. Nida, Y. Yabe, K. Sakoda, N. Sato, M. Ito, A. Hasegawa, Y. Asano, A. Hasemi, T. Demachi, and Y. Yajima, Hypocenter and focal mechanism distribution of aftershocks of July 26, 2003, M6.2 northern Miyagi earthquake revealed by temporary observations, J. Seism. Soc. Japan (Zisin), 2003 (in press) (in Japanese with English abstract).

Waldhauser, F., HypoDD: A computer program to compute doubledifference hypocenter locations, US Geol Surv Open File Rep, 01-113 25 pp., 2001.

Waldhauser, F. and W. L. Ellsworth, A double-difference earthquake location algorithm: method and application to the Northern Hayward fault, Bulletin of Seismological Society of America, 90, 1353-1368, 2000.

Yagi, Y., Y. Ito, Y. Asano, and S. Sekine, Fore-shock, Main-shock and the largest aftershock associated with the July 262003 Miyagi-ken-hokubu, Japan, earthquake, Abstract for the 2003 Fall Meeting of Seismological Society of Japan, A086, 2003.

T. Okada (e-mail: okada@aob.geophys.tohoku.ac.jp), N. Umino, and A. Hasegawa 